\title{
O DILEMA RACIAL NAS AMÉRICAS
}

REITER, Bernd; e SIMMONS, Kimberley Eison (orgs). AfroDescendants: Identity, and the Struggle for Development in the Americas. East Lansing: Michigan State University Press, 2012. 314 p.

$E_{\text {ste livro é um bem-vindo acréscimo }}$ à bibliografia sobre desenvolvimento $\mathrm{e}$ relações raciais de uma perspectiva comparativa. Trata-se de uma coletânea de artigos originalmente apresentados num colóquio ("Reexamining the Black Atlantic: Afro-Descendants Still at the Bottom?") realizado no Institute for the Study of Latin America and the Caribbean (ISLAC) da Universidade do Sul da Flórida, em abril de 2010. O colóquio analisou o papel de organizações internacionais na disseminação transnacional da consciência racial; almejou, também, investigar a evolução e os resultados da emersão da consciência de grupo através das Américas. Talvez o mais importante dos objetivos específicos tenha sido analisar a introdução e os efeitos das categorias raciais da América do Norte em países como o Brasil. Trata-se de imperialismo cultural ou de um ca- minho para derrubar mitos de unidade nacional ("democracia racial", "la raza de bronze" etc.) que impedem o progresso das pessoas de ancestralidade africana?

O livro é ambicioso em seus objetivos. Os capítulos são variados, indo de detalhadas explicações sobre métodos estatísticos a narrativas de primeira mão sobre conflitos burocráticos no interior da máquina do Estado. Esta variedade é uma das forças e uma das fraquezas do trabalho. AfroDescendants, Identity and Struggle é dividido em quarto partes: 1) "The Black Atlantic Reexamined" / O Attântico negro reexaminado; 2) "DoubleConsciousness and Black IdentityGlobalized" / Dupla consciência e identidade negra globalizada; 3) "Racism in 'Raceless' Societies and the State: The Difficulties of Addressing What Ought Not Exist" / Racismo em sociedades 'sem raça' e o Estado: a difi- 
culdade em abordar o que não devia existir; 4) "Migration, Diasporas, and the Importance of Local Knowledge" / Migração, diásporas e a importância do saber local. Algumas das contribuições têm um tom altamente acadêmico, enquanto outras são peças de ativismo politicamente orientado. A primeira parte contém ensaios do antropólogo cultural Faye V. Harrison e de Darién J. Davis, Tianna Paschel e Judith Morrison. Harrison relata os recentes esforços de ativistas e políticos para unir a dispersa diáspora africana e cita como exemplo as conferências e grupos de planejamento colocados em campo por organizações internacionais (por exemplo, a Conferência de Durban em 2001). Davis, Paschel e Morrison escrevem sobre "pan-afro-americanismo". Ambos os ensaios descrevem em linhas gerais os esforços dos afro-americanos (aqui sempre usado como negros estadonidenses) para influenciar afrodescendentes nas Américas. Nos dois ensaios há uma fé no reformismo e na confiabilidade das instituições estabelecidas (incluindo bancos norte-americanos) para ajudar na luta contra a discriminação racial na América Latina. Davis et alii realmente se dão conta de que existem tensões nas "relações de poder norte-sul". E, corretamente, advertem contra o "enfraquecimento da diversidade, a fragmentação política e a disputa de espaço dentro desses movimentos" (p. 43).
A segunda parte vai de discussões gerais sobre redes pan-africanistas a discussões sobre países específicos. República Dominicana, Nicarágua, Colômbia e Brasil são discutidos nesses ensaios por Lauren Derby, Kimberly Simmons, Juliet Hooker, Leonardo Reales Jiménez e Seth Racusen. Derby e Simmons abordam a República Dominicana e observam o efeito da imigração haitiana na autopercepção nacional. $\mathrm{O}$ ensaio de Juliet Hooker sobre a Nicarágua ocupa-se da identidade negra crioula. Ela mostra que os chamados criollos vivem numa sociedade altamente multicultural; o ensaio nos deixa curiosos sobre os demais grupos da mistura racial e se os limites entre as várias etnicidades são fluidos ou fixos. Reales Jiménez provê uma boa visão histórica da emergência da consciência negra na Colômbia. É importante ressaltar que ele evita essencialismos, advertindo que "não se pode admitir que afro-colombianos tenham uma identidade étnica 'natural'" (p. 122). A promoção agressiva de uma identidade pode fazer alguns indivíduos "se afastarem do processo de construção de identidade afro-colombiana" (p. 122). A contribuição de Seth Racusen, "The Grammar of Color Identity in Brazil", é uma detalhada e estimulante análise sociolinguística da taxonomia de cor / raça no Brasil. Ele examina vários levantamentos estatísticos das escolhas dos brasilei- 
ros para identificar cor / raça. Conclui que raça e cor devem ser usadas em ações afirmativas, mas devem ser combinadas com indicadores de classe socioeconômica. Para fins de admissão na universidade, ele acredita que o termo "afro-descendente é mais inclusivo do que negro" (p. 169). O ensaio de Racusen é um complemento interessante ao de Eison Simmons. Racusen percebe a tendência dos informantes a branquearem a si mesmos e aos outros como um possível exemplo de "autoaversão fanoniana" (p. 165). Na sua discussão sobre estudantes afro-americanos na República Dominicana, Eison Simmons comenta a tendência dos dominicanos em valorizar raízes não africanas. $\mathrm{O}$ que é mais interessante na sua discussão é a reação dos estudantes afroamericanos quando confrontados com a realidade social dominicana. Afastados do binômio norte-americano branco / preto, esses

\begin{abstract}
afro-americanos passaram a entender a 'mestiçagem' e a negritude dominicana, enquanto dominicanos passaram a entender a negritude americana, criando um deslocamento epistemológico em ambos os termos, mestiçagem e negritude, para americanos e dominicanos (p. 88).
\end{abstract}

Mistura é parte da realidade biológica e social. O que os autores deixam de reconhecer é que a aversão pela mistura racial dos norte-americanos pode estar moldada por precei- tos racistas, assim como o não reconhecimento da negritude pelos brasileiros. Este resenhista observaria que o fato de brasileiros verem gradações de cor deve deixar de nos fascinar. Estudos recentes nos Estados Unidos, especialmente após a eleição de Barack Obama, mostram que os americanos, sejam brancos ou negros, são altamente sensíveis à cor, embora discussões sobre cor, em oposição à raça, sejam um tabu social. Norte-americanos raramente mencionam cor, exceto em relatórios policiais. Em 1978, um estudo sobre "quem é quem entre os negros americanos" já mostrava que a maior parte daqueles listados como de classe média tinha ancestrais que já eram livres antes da abolição da escravatura em 1865 e que um número desproporcional deles era de mulatos. Evidências bem mais recentes indicam que os afro-americanos de "pele mais clara" ganham 83 por cento do que ganham os brancos; os mais escuros ganham 52 por cento. ${ }^{1}$

\footnotetext{
F. James Davis, Who is Black? One Nation's Definition, University Park, PA: Pennsylvania State University Press, 1994, p. 76, citando Elizabeth Mullins e Paul Sites, "The Origins Contemporary Black Americans: A ThreeGenerational Analysis of Social Origin", American Sociological Review, n. 49 (1984), pp. 679-80. Ver também Eduardo BonillaSilva e David R. Dietrich, "The Latin Americanization of U.S. Race Relations, A New Pigmentocracy", in Evelyn Nakano Glenn (eds.), Shades of Difference, Why Skin Color Matters (Stanford, CA: Stanford University Press, 2009).
} 
A terceira parte, "Racism in 'Raceless' Societies and the State", abre com o ensaio de Paula Lezama, "AfroColombian Welfare: An Application of Amartya Sen's Capability Approach Using Multiple Indicators Multiple Causes Modeling" (MIMIC).

Seu propósito é mostrar que a posição dos afro-colombianos não é somente um resultado de pobreza baseada em classe, mas resulta também da discriminação. Infelizmente, este ensaio é abundante em metodologia, mas suas conclusões são pouco elaboradas. O ensaio seguinte é de Gladys Mitchell-Walthour, "Racism in a Racialized Democracy and Support for Affirmative Action Policy in Salvador and São Paulo, Brazil". É um estudo claro em termos tanto da metodologia quanto dos resultados. Entrevistados mais jovens foram mais propensos a apoiar as ações afirmativas do que os mais velhos. Afrobrasileiros foram tão mais tendentes a apoiar ações afirmativas quanto maior a sua renda.

Curiosamente, a mobilização racial seria mais disseminada em São Paulo, onde os afro-brasileiros são uma minoria, do que em Salvador, onde são maioria. A contribuição de MitchellWalthour é seguida por um breve panorama sobre mulheres na América Latina e no Caribe, de Altagracia Balcácer e Dorotea Wilson. Devido a sua brevidade, o ensaio não se concentra em detalhes e lê-se como se fosse uma lista de desejos muito gerais para melhorar a vida das mulheres na diáspora negra.

A quarta parte, "Migration, Diasporas, and the Importance of Local Knowledge" ocupa-se de tópicos de cultura e produção cultural. Amanda D. Concha-Holmes encarrega-se de religião iorubá em Cuba. Adverte contra o perigo de folclorização das práticas religiosas de matriz Africana. Destaca que elas foram criminalizadas por muito tempo. Quando foram finalmente reconhecidas como parte da cultura nacional, elas foram condenadas por suas amarras culturais. Isso permaneceu inalterado desde a Revolução Cubana em 1959. A ensaísta exorta-nos a perceber que a prática religiosa de matriz africana contém modos de saber que enriquecem a totalidade da cultura (conhecimento ecológico, por exemplo). Judith M. Anderson vem a seguir com "Neoliberal Dilemmas: Diaspora, Displacement and Development in Buenos Aires". Anderson descreve brevemente e em linhas gerais as várias vertentes de afro-argentinos (descendentes de escravos da era colonial, descendentes de imigrantes caboverdianos, os recentes imigrantes africanos). Ressalta que esses grupos têm se acotovelado uns aos outros e têm dificuldade de formar uma agenda comum. Talvez pouco desenvolvida seja a sua referência à utilização do termo "negro" para os pobres em ge- 
ral e a complexa relação entre o pobre genérico e as pessoas que traçam a sua ascendência à África. A Argentina representa uma confluência interessante de taxonomias raciais e de classe. Em contraste com a densa apresentação metodológica de Lezama, Anderson evita o método e a teoria. Em seu lugar, de modo polêmico, ela interpõe numerosas vinhetas de suas batalhas pessoais com os colegas. $\mathrm{O}$ ensaio de Mamyrah A. DougéProsper, "Pluralizing Race", completa o livro. Ao contrário dos outros ensaios, trata-se de um caso norteamericano, Take Back the Land / Tome de volta a terra, um movimento de 2006, em Miami, Florida. O movimento foi iniciado em grande parte por homens afro-americanos idosos que montaram um acampamento para protestar contra a falta de moradia. O assentamento, Umoja Village, foi finalmente destruído pelo fogo. Habitantes e ativistas exigiram que a municipalidade fizesse alguma coisa. O protesto evoluiu para o movimento Take Back the Housing / Tome de volta a casa. Curiosamente, este ensaio diz pouco especificamente sobre raça. A maioria das pessoas envolvidas eram afro-americanas e a narrativa do "'Take Back the Land' voltou a re-territorializar a negritude dentro do contexto histórico nacional dos EUA" (p.299). Sim, mas qual era a relação do movimento com os imigrantes haitianos, a comunidade cu- bano-americana e o resto da comunidade afro-americana?

Como foi dito, os objetivos de Afro-Descendants, Identity, and the Struggle for Development in the Americas são ambiciosos. O livro mostra que as conceitualizações norte-americanas sobre raça têm e continuarão a ter um impacto sobre o Caribe e as Américas Central e do Sul. Bernd Reiter pergunta no prólogo do livro se

a aplicação das categorias raciais norte-americanas às análises e estabelecimento de políticas sociais em países como o Brasil [é] parte da 'razão imperialista' [a la Pierre Bourdieu ${ }^{2}$ ou [é parte] do diálogo interamericano entre os grupos socialmente excluídos e as agências que os apoiam?.

A obra argui contra aqueles que, como Bourdieu, veriam a América Latina para além da recapitulação do binômio preto / branco. E, de fato, deveria ser óbvio o fato de que pessoas de ascendência africana são marginalizadas e empobrecidas em muitas partes da América Latina (como foi visto nos ensaios de Reales Jiménez e Paula Lezama sobre afrocolombianos). Eu argumentaria que a mobilização racial, quando casada

\footnotetext{
2 Pierre Bourdieu e Loric Wacquant, "On the Cunning of Imperialist Reason", Theory, Culture and Society, v. 16, n 1 (1999), pp. 41-58.
} 
com reconhecimento de desigualdades de classe generalizadas, é necessária em muitas partes da América Latina e do Caribe. Contudo, por sua natureza multiforme, "raça" pode não ser uma ferramenta de mobilização útil em todo lugar. O capítulo de Lauren Derby fala dos haitianos na República Dominicana, mas alguém perguntaria se raça por si só é uma solução para justiça social em qualquer parte da ilha de Hispañola (ainda mais problemático seria Porto Rico, onde mais de $80 \%$ da população defende sua branquitude).

Por uma estranha coincidência, ideias de etnicidade cultivadas no sul das Américas estão se insinuando no norte. Mesmo sendo exportado, o binômio preto / branco está se desintegrando nos Estados Unidos. Para a América do Norte, a América Latina produz "latinos", e mesmo a mestizaje / mestiçagem é silenciada. Eu diria que, em 2012, a negritude para os recém-chegados aos Estados Unidos é subsumida num mito de democracia racial tão amplo como nunca imaginado pelas elites latino-americanas do início do século XX. A identidade "latina" do discurso norte-americano é tanto uma realidade - e uma construção - quanto a democracia racial há muito tempo consagrada na consciência dos brasileiros e de outros. No final de 2011, Jorge Castañeda, literateur mexicano e ex-ministro do exterior, escreveu um editorial bas- tante profético no New York Times intitulado "What Latin America Can Teach Us"/ O que a América Latina pode nos ensinar. ${ }^{3}$ Ele advertia os americanos contra o desenvolvimento nos Estados Unidos do esgarçamento das divisões de classe típicos de sua região, a América Latina. Oportunidades frustradas em suas pátrias forçam os migrantes mestiços para o norte. Eu observo que, na nova terra, paradoxalmente, a mestiçagem dos recém-chegados pode ser lavada em uma banheira quente de pan-etnicidade. $\mathrm{O}$ camponês se une ao dono da terra, não economicamente, mas como aspiração.

O que chamamos de "América Latina" tem milhões de pessoas de ascendência Africana. Elas pertencem a várias classes e movimentos sociais. Além disso, elas podem se definir como membros de uma ecumene ibérica, muito mais cômoda e elaborada do que qualquer "Atlântico Negro". Na minha visão, a emergência dos "latinos" nos Estados Unidos se contrapõe à narrativa afro-americana do binômio branco / preto que proporcionou as condições para o movimento pelos direitos civis norte-americanos. Em 2007, hispânicos / lati-

\footnotetext{
3 Jorge Castañeda, "What Latin America Can Teach Us", The New York Times, Op$E d, 11$ de dezembro de 2011. Ver também do mesmo autor, The Mexican Shock: Its Meaning for the United States, Nova York: New Press, 1996; e Mañana Forever, Nova York: Knopf, 2011.
} 
nos, um grupo etno-racial grande o suficiente para incluir jogadores de beisebol dominicanos, trabalhadores rurais mexicanos e empresários cubanos, tinha alcançado a posição de "maior minoria" dos Estados Unidos. Neste país, essa mudança na demografia étnica / racial tem muito a dizer sobre a escolha de representantes pelo sistema eleitoral distrital, sobre definições do que constitui uma escola integrada e que blocos eleitorais podem ser confrontados com os demais. Também tem muito a dizer sobre o papel da ideologia da ascensão social ao nomear os jogadores no jogo de identidades americano. Nacionalmente, menos de $5 \%$ do grupo latino / hispânico afirma sua ascendência africana. Mesmo a conferência que produziu Afro-Descendants foi realizada na Flórida, um estado com uma crescente população "latina". De fato, a Flórida avançou além do binômio branco / preto implícito em muitos dos ensaios desta coletânea. Com exceção do ensaio de Concha-Holmes sobre religião, Cuba não aparece na coleção. No entanto, os cubanos na Flórida mostram a grande complexidade do binômio branco / preto no século XXI. Em grande parte autoidentificados como "brancos", eles são parte de um grupo popularmente apelidado de brown (marrom). ${ }^{4}$ Em 2012, o Censo dos Estados Unidos considera transformar "hispânicos / latinos" numa categoria mista não sujeita a divisão em raça. De que maneira obras como Afrodescendents ajudam a questionar a nova construção social, na medida que mais e mais migrantes do sul chegarem aos Estados Unidos? Muitos deles se verão como "afro-descendentes”, ou se apegarão cada vez mais a uma identidade latina que substitui o Atlântico Negro?

Ibrahim Sundiata sundiata@brandeis.edu Brandeis University Tradução de Mariângela de Mattos Nogueira

\footnotetext{
Sobre políticas interétnicas para cubanos e negros em Miami, ver Mark Q. Sawyer, Racial Politics in Post-Revolutionary $C u b a$, Nova York: Cambridge University Press, 2006. Especialmente relevante é o capítulo 7, "Racial Politics in Miami: Ninety Miles and a World Away".
} 